\title{
Effect of Fetal Undernutrition and Postnatal Overfeeding on Rat Adipose Tissue and Organ Growth at Early Stages of Postnatal Development
}

\section{MUÑOZ-VALVERDE ${ }^{2}$, P. RODRÍGUEZ-RODRÍGUEZ ${ }^{1}$, P. Y. GUTIERREZ-ARZAPALO ${ }^{1}$, A. L. LÓPEZ DE PABLO ${ }^{1}$, M. CARMEN GONZÁLEZ ${ }^{1}$, R. LÓPEZ-GIMÉNEZ ${ }^{3}$, B. SOMOZA ${ }^{4}$, S. M. ARRIBAS ${ }^{1}$}

${ }^{1}$ Department of Physiology, ${ }^{2}$ Laboratory of Animal Facility and ${ }^{3}$ Department of Preventive Medicine, Public Health and Microbiology, School of Medicine, Universidad Autónoma de Madrid, Madrid, ${ }^{4}$ Department of Pharmaceutical and Food Sciences, School of Pharmacy, Universidad San Pablo-CEU, Madrid, Spain

Received April 20, 2014

Accepted July 1, 2014

On-line December 3, 2014

\section{Summary}

Intrauterine and perinatal life are critical periods for programming of cardiometabolic diseases. However, their relative role remains controversial. We aimed to assess, at weaning, sexdependent alterations induced by fetal or postnatal nutritional interventions on key organs for metabolic and cardiovascular control. Fetal undernutrition was induced by dam food restriction ( $50 \%$ from mid-gestation to delivery) returning to ad libitum throughout lactation (Maternal Undernutrition, MUN, 12 pups/litter). Postnatal overfeeding (POF) was induced by litter size reduction from normally fed dams (4 pups/litter). Compared to control, female and male MUN offspring exhibited: 1) low birth weight and accelerated growth, reaching similar weight and tibial length by weaning, 2) increased glycemia, liver and white fat weights; 3) increased ventricular weight and tendency to reduced kidney weight (males only). Female and male POF offspring showed: 1) accelerated growth; 2) increased glycemia, liver and white fat weights; 3) unchanged heart and kidney weights. In conclusion, postnatal accelerated growth, with or without fetal undernutrition, induces early alterations relevant for metabolic disease programming, while fetal undernutrition is required for heart abnormalities. The progression of cardiac alterations and their role on hypertension development needs to be evaluated. The similarities between sexes in pre-pubertal rats suggest a role of sex-hormones in female protection against programming.

\section{Key words}

Adipose tissue - Cardiometabolic programming - Catch-up growth • Maternal undernutrition • Postnatal overfeeding

\section{Corresponding author}

S. M. Arribas, Departamento de Fisiología, Facultad de Medicina, Universidad Autónoma de Madrid, C/ Arzobispo Morcillo 2, Madrid 28029, Spain. Fax: +34 914975478.

E-mail: silvia.arribas@uam.es

\section{Introduction}

Mother-offspring interactions during intrauterine life and perinatal suckling period are critical for the manifestation of several diseases in adulthood, particularly cardiometabolic diseases (CMD), process known as fetal or perinatal programming (Barker and Osmond 1986, Bateson et al. 2004, Gluckman et al. 2008). Among other influences it is well recognized the key role of fetal undernutrition, as demonstrated by a number of epidemiological studies (Heijmans et al. 2008, Huxley et al. 2007, Lumey et al. 2009, Ravelli et al. 1998). This is a relevant problem, since CMD are one of the leading causes of death and disability worldwide and because fetal undernutrition and low birth weight remain prevalent in many countries. In poorly developed regions it is mainly due to insufficient food access, while in 
industrialized societies it is related to social and gender reasons, such as severe gestational dietary restriction to remain slim or the delay of first pregnancy, which increases the prevalence of feto-placental alterations, premature babies and multiple pregnancies (Norman 2010, Poston 2011). The above epidemiological data have been confirmed in animal models, which have been useful to gain insight in the underlying mechanisms linking nutritional alterations during perinatal life and the development of adult disease (Bateson et al. 2004). These studies have demonstrated in several species (rats, guinea pigs, mice, calf, sheep) that fetal undernutrition, due to nutrient restriction during pregnancy or uterine artery ligation, produce offspring with low birth weight and features of CMD in adult age (Langley-Evans et al. 1999, Nielsen et al. 2013, Ozaki et al. 2001).

Early postnatal feeding patterns also seem to be critical for adult health, as evidenced by the link between accelerated postnatal growth due to reduction of exclusive breast feeding time in humans and the development of hypertension, dyslipemia, insulin resistance and obesity (Arenz et al. 2004, Singhal and Lucas 2004). Similarly, in animal models postnatal overfeeding, induced by reduction of litter size at birth, has also been linked to elevated insulin (Habbout et al. 2013) and altered fat metabolism in adult life (Balonan and Sheng 2000).

While there is consensus regarding the effects of fetal and early postnatal nutrition patterns in adult CMD development, their relative contribution has not been clarified, particularly at young age. Some authors postulate that the causal link between fetal malnutrition and CMD is the postnatal catch-up growth period that follows in utero nutrient restriction rather than fetal programming per se (Corpeleijn et al. 2013, Kerkhof et al. 2012). This controversy might be related to the fact that the majority of the studies on CMD programming assess the long term consequences of an early intervention and they omit the study of the perinatal period. This issue has been put forward by Kunes and coworkers who suggested the key importance of the period where the organism is dependent on the mother, i.e. from fertilization to weaning, particularly in the context of hypertension development (Kunes et al. 2012). In addition, we consider relevant to gain knowledge on specific alterations taking place during perinatal critical windows of development, where there is still enough plasticity for a preventive intervention to counteract CMD programming. In order to gain insight in this problem we studied, at weaning, growth of several tissues and organs key for cardiovascular and metabolic control in the offspring from rats exposed to fetal or perinatal nutritional interventions. Specifically, we compared the consequences of suboptimal fetal nutrition (induced by dam food restriction) and postnatal overfeeding (induced by reduction of litter size at birth from normally fed dams) on glycemia, heart, kidney and liver weights and fat accumulation in the offspring from Sprague Dawley rats.

On the other hand, perinatal programming seems to have a sex-dependent component, being the deleterious long-term cardiovascular and metabolic consequences less prominent in females (Howie et al. 2012, Ozaki et al. 2001). Female protection against hypertension programming has been described only when the fetal stress is mild, while severe interventions affect both males and females (Vehaskari and Woods 2005) and can be due to the advanced developmental maturation of females compared to males. Alternatively, it can be related to the later protection by estrogens. Therefore, we also aimed to assess in our rat models if sex-dependent differences can be evidenced at early stages of life, before sexual maturity, and the relative importance of intrauterine and postnatal life.

\section{Materials and Methods}

Experiments were performed in Sprague Dawley rats from the colony maintained at the Animal House facility of the Universidad Autónoma de Madrid. All experimental procedures conformed to the Guidelines for the Care and Use of Laboratory Animals (NIH publication No. 85-23, revised in 1996), the Spanish legislation (RD 1201/2005) and they were approved by the Ethics Review Board of Universidad Autónoma de Madrid.

The rats were housed in buckets 36.5/21.5/18.5 $\mathrm{cm}$ (length/width/height) on aspen wood bedding, under controlled conditions of $22{ }^{\circ} \mathrm{C}$ temperature, relative humidity $40 \%$ and 12/12 light/dark photoperiod. They were fed with breeding diet SAFE A03 (Safe Augy, France) containing $51.7 \%$ carbohydrates, $21.4 \%$ protein, $5.1 \%$ lipids, $3.9 \%$ fiber, $5.7 \%$ minerals and $12.2 \%$ humidity. Drinking water was filtered by UV, mechanical and chemical treatments and provided ad libitum in all cases. The animal health monitoring indicated that they were free from any pathogen that may interact with the parameters studied. The health and welfare of the animals 
was monitored by staff at least once a day.

\section{Maternal Undernutrition (MUN) model}

12 week-old dams were used and day 1 of gestation was determined by observation of sperm in the vaginal smear. Firstly, we determined in a group of dams that the maximum intake of rat chow in pregnant rats was 24 grams/day. Dams were divided in two groups: one with ad libitum diet throughout pregnancy (Control group, $\mathrm{C}, \mathrm{n}=12$ dams) and the other with ad libitum diet during the first 10 days of gestation and $50 \%$ of the usual daily intake from day 11 to the end of pregnancy (MUN, $\mathrm{n}=12$ dams). After delivery, both $\mathrm{C}$ and MUN rats were given food ad libitum during suckling period and food intake of the dams was weighted every 2 days. The dams were weighted at day 1 of pregnancy, at day 10 and 1-2 days prior to delivery to calculate weight gain during the first and second half of gestation.

$24 \mathrm{~h}$ after birth the pups were sexed and weighed individually and the litter was standardized to 12 individuals, 6 males and 6 females if possible (smaller litters were not used). The rats were also weighted at day 7 and at weaning, which was performed at the age of 21 days. At this age some of the animals were sacrificed to quantify glycemia, tibial length, as well as the weight of heart, kidney, liver and fat deposits; the rest of the offspring was maintained for other studies.

\section{Postnatal Overfeeding (POF) model}

We used 12 week-old dams fed ad libitum regular diet throughout gestation and suckling period with the litters reduced at birth to 4 pups, 2 males and 2 females ( $n=12$ dams). The offspring was weighted at birth, at day 7 and at weaning (21 days).

\section{Experimental protocols in the offspring at weaning}

At day 21 after birth, the pups were separated from the dam and a blood sample was immediately taken from the tail to determine glycemia with a glucometer (Accu-check Aviva, Roche). Glycemia was always measured at 9:00 $\mathrm{h}$ and we did not perform a fasting period in order to avoid the maternal separation stress.

Then, the pups were weighted and euthanized in a $\mathrm{CO}_{2}$ atmosphere, followed by dissection of tibia, liver, heart (ventricles) and kidney and the following fat deposits: mesenteric (whole mesentery except the intestines), peri-renal (along the dorsal abdominal cavity and surrounding both kidneys), gonadal (around the ovaries or epididymis), subcutaneous (surrounding the skin of both lower limbs) and brown fat (from the interscapular region). Immediately after dissection, tibial length was measured with a digital caliper (Comecta, Nessler, Spain) and the organs and fat deposits were weighted using an analytical balance (Boeco, Germany). Organ weights were expressed as relative weights (organ weight/body weight).

Perivascular mesenteric adipocyte size was assessed by confocal microscopy (Gil-Ortega et al. 2010). Briefly, a small sample from mesenteric adipose tissue was fixed in $4 \%$ paraformaldehyde. Thereafter, the tissue was mounted intact between a slide provided with a small well filled with mounting medium (Citifluor, Aname, Spain) and a coverglass. The samples were visualized with a Leica TCS SP2 confocal system (Leica Microsystems ${ }^{\circledR}$, Wetzlar; Germany) using the $488 \mathrm{~nm} / 515 \mathrm{~nm}$ line, since adipocytes exhibit autofluorescence at this wavelength. Five random images were captured with a 40x objective. The area occupied by adipocytes and their number were quantified by Metamorph image analysis software (Universal Imaging Co., UK) and the mean adipocyte area was calculated.

\section{Statistical analysis}

Sample size was calculated as 12 rats per group. This calculation was performed based on those parameters which exhibited the highest variability, assuming a probability error of alpha type of $5 \%$ $(p<0.05)$ and potency of $80 \%$. Statistical analysis was performed with SPSS software (v 17.0). Data are expressed as mean \pm SEM and statistical significance was analyzed with one-way ANOVA followed by a NewmanKeuls post hoc test. Statistical significant level was established at $\mathrm{p}<0.05$.

Table 1. Effect of food restriction during gestation on dams body weight gain and on food intake during lactation.

\begin{tabular}{lrc}
\hline & $\begin{array}{c}\text { C } \\
(\mathbf{n}=\mathbf{1 2})\end{array}$ & $\begin{array}{c}\text { MUN } \\
(\mathbf{n}=\mathbf{1 2})\end{array}$ \\
\hline$\Delta$ Body weight (day G1-10) & $36.7 \pm 4.4$ & $35.4 \pm 3.7$ \\
$\Delta$ Body weight (day G11-21) & $97.5 \pm 4.4$ & $39.0 \pm 5.8^{*}$ \\
Mean offood intake day P2 & $27.16 \pm 8.3$ & $29.8 \pm 4.6$ \\
Mean offood intake day P10 & $44.1 \pm 6.3$ & $60.4 \pm 3.4^{*}$ \\
Mean offood intake day P21 & $51.6 \pm 7.8$ & $68.2 \pm 5.7$ \\
\hline
\end{tabular}

C, control; MUN, maternal undernutrition; $n$, number of rats; * $\mathrm{p}<0.05$ compared to control dams; $\mathrm{G}=$ gestation; $\mathrm{P}=$ postnatal 


\section{Results}

\section{Parameters measured in the dams}

MUN dams exhibited similar growth increase during the first half of gestation (exposed to ad libitum diet) compared to control group, while they exhibited significantly lower body weight gain during the second half of pregnancy (when they were exposed to $50 \%$ food reduction). MUN dams returned to ad libitum diet during lactation and during this period there was a tendency towards a larger food intake compared to controls, reaching statistical difference only by mid lactation (day 10) (Table 1).

\section{A) Body weight (24 h)}

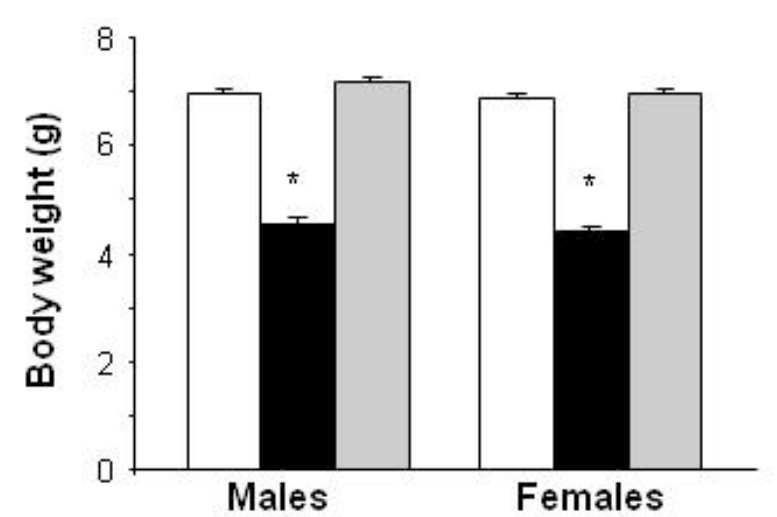

\section{Offspring growth parameters}

At birth, offspring from MUN rats had significantly smaller body weight compared to $\mathrm{C}$ group in both males and females (36\% smaller). Birth body weight of POF offspring did not differ from $\mathrm{C}$ rats (Fig. 1A). At postnatal day 7, MUN offspring still exhibited significantly lower body weight compared to their sex-matched controls, but had accelerated growth. Thus, males were now only $14 \%$ smaller and females $11 \%$ smaller compared to controls. During the first week of life POF offspring exhibited a marked acceleration in growth, being body weight $57 \%$ and $63 \%$ larger in males and females respectively, compared to control rats (Fig. 1B).

\section{B) Body weight (7 days)}

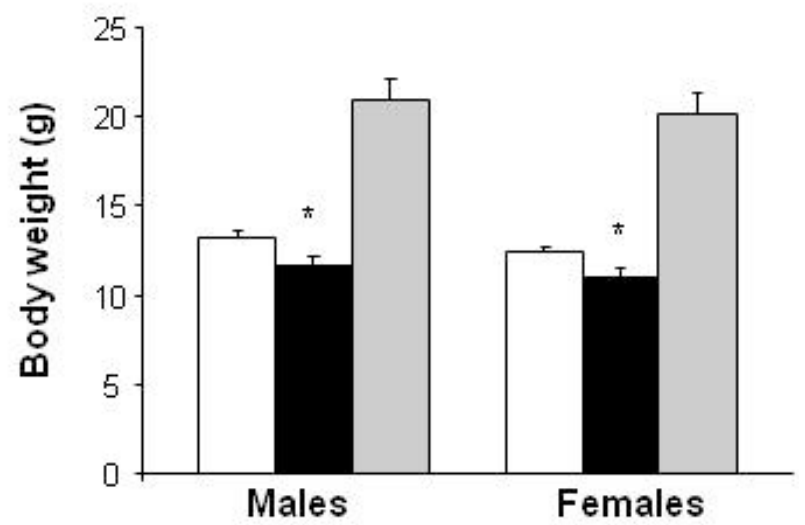

C) Body weight (21 days)

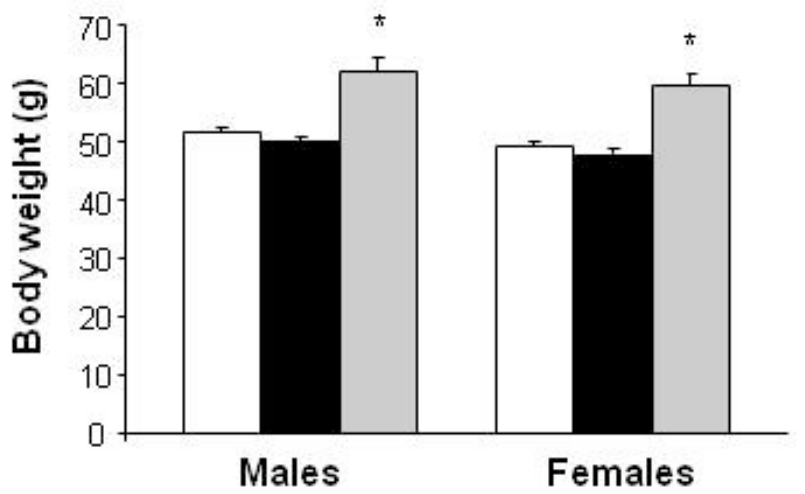

D) Tibial length (21 days)

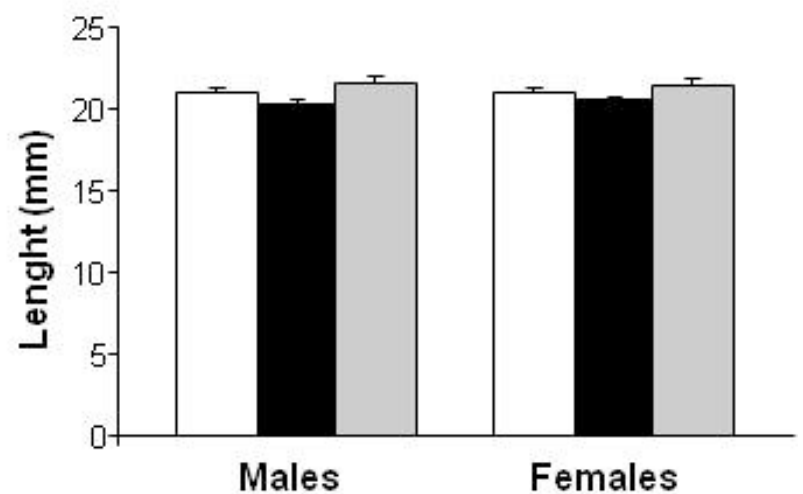

Fig. 1. Body weight at birth (A), at day 7 (B) and at day 21 (C) and tibial length at day 21 (D) in male and female MUN, C and POF offspring. C, rats with ad libitum diet in pregnancy and 12 rats/litter; MUN, rats exposed to $50 \%$ of the normal daily intake during the second half of pregnancy and 12 rats/litter; POF, rats with ad libitum diet during pregnancy and 4 pups/litter. In parenthesis is shown the number of rats; $* p<0.05$ when compared to $C$ group. 


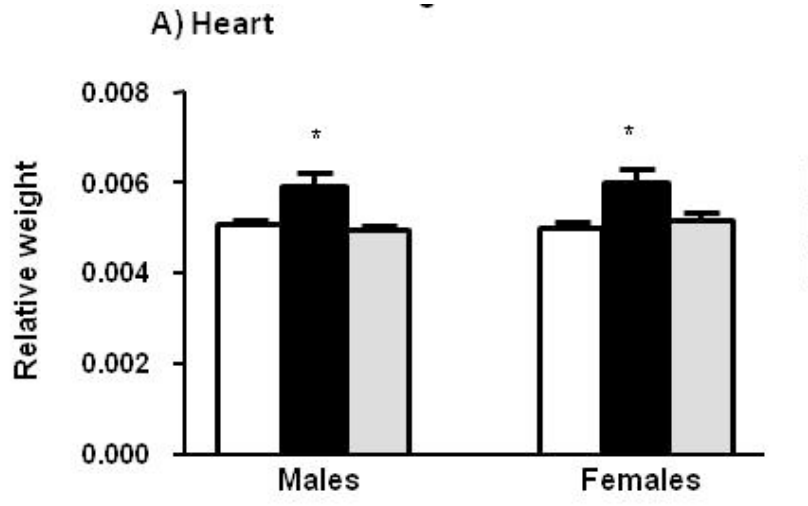

B) Kidney

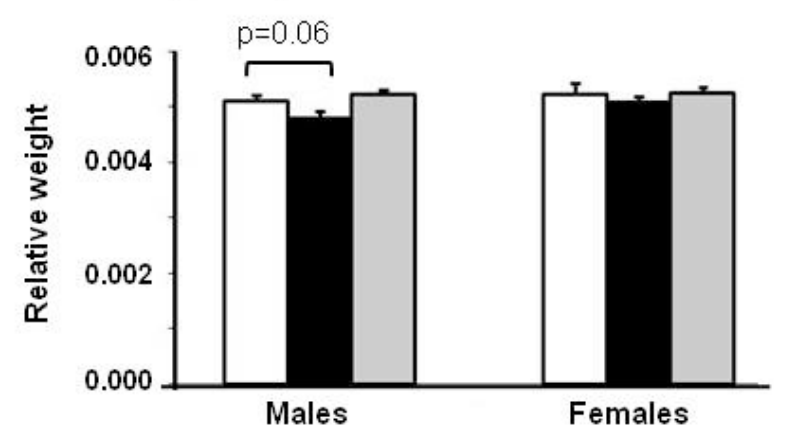

C) Liver

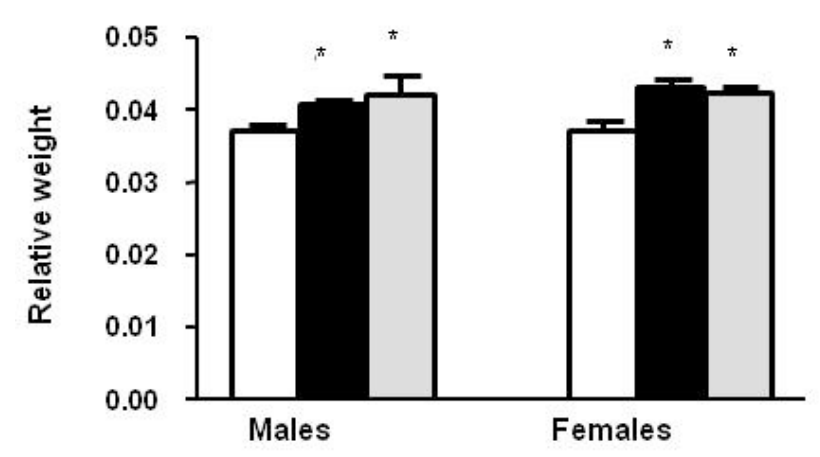

At day 21 , body weight was not significantly different in male and female MUN offspring compared to their sex-matched $\mathrm{C}$ rats. At this age body weight of POF rats was $20 \%$ and $17 \%$ larger in males and females, respectively, compared to $\mathrm{C}$ offspring (Fig. 1C). At day 21 there were no significant differences in tibial length among experimental groups in either males or females (Fig. 1D).

There were no statistical differences between males and females within experimental groups at any of the ages studied.
Fig. 2. Heart (A) and kidney (B) and liver (C) weight relative to body weight in male and female MUN, $\mathrm{C}$ and POF offspring. $\mathrm{C}$, rats with ad libitum diet in pregnancy and 12 rats/litter; MUN, rats exposed to $50 \%$ of the normal daily intake during the second half of pregnancy and 12 rats/litter; POF, rats with ad libitum diet during pregnancy and 4 pups/litter. In parenthesis is shown the number of rats; $* \mathrm{p}<0.05$ when compared to $\mathrm{C}$ group.
C $(14 \delta, 14)$

MUN $\left(14 \delta^{*}, 14\right)$

$\operatorname{POF}\left(12 \delta^{x}, 12\right)$ 
sex-matched rats. There were no statistical differences between males and females in any of the experimental groups (Fig. 2C).
Blood glucose was significantly elevated in both males and females from MUN and POF rats compared to C sex-matched counterparts (Table 2).

Table 2. Glycemia (mg/dl) in C, MUN and POF offspring at day 21.

\begin{tabular}{ccccccc}
\hline & \multicolumn{2}{c}{ Control } & \multicolumn{2}{c}{ MUN } & \multicolumn{2}{c}{ POF } \\
\cline { 2 - 7 } & $\begin{array}{c}\text { Males } \\
(\mathbf{n}=\mathbf{1 2})\end{array}$ & $\begin{array}{c}\text { Females } \\
(\mathbf{n}=\mathbf{1 1})\end{array}$ & $\begin{array}{c}\text { Males } \\
(\mathbf{n}=\mathbf{1 2})\end{array}$ & $\begin{array}{c}\text { Females } \\
(\mathbf{n}=\mathbf{1 2})\end{array}$ & $\begin{array}{c}\text { Males } \\
(\mathbf{n}=\mathbf{1 1})\end{array}$ & $\begin{array}{c}\text { Females } \\
(\mathbf{n}=\mathbf{1 2})\end{array}$ \\
\hline Glycemia & $114.8 \pm 9.3$ & $101.1 \pm 8.6$ & $151.6 \pm 2.0 *$ & $148.8 \pm 3.2 *$ & $152.2 \pm 4.8^{*}$ & $159.2 \pm 5.2 *$ \\
\hline
\end{tabular}

C, control; MUN, maternal undernutrition, POF, postnatal overfeeding; n, number of rats; * $p<0.05$ with respect to control

A)

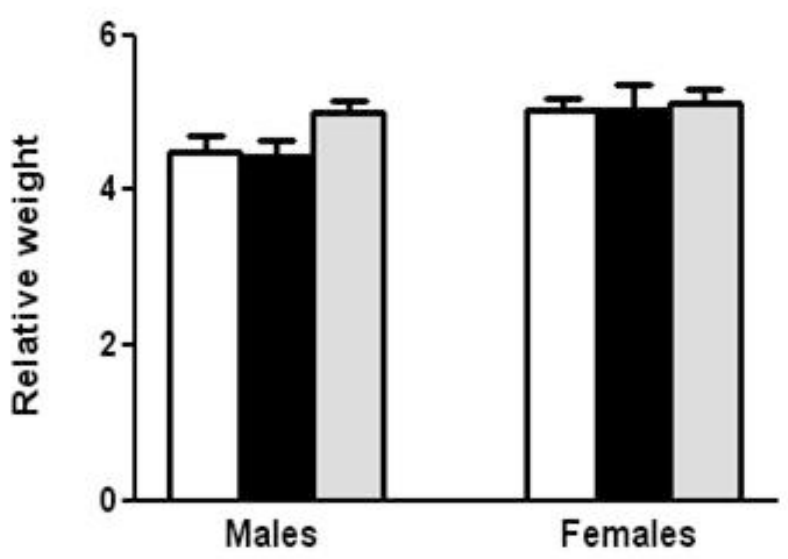

B) Subcutaneous Fat

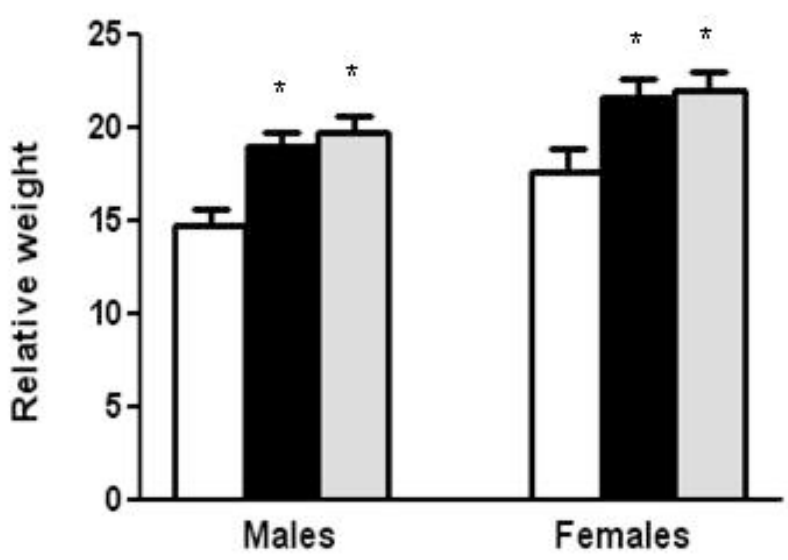

$\mathrm{C}(14 \delta, 149)$

MUN $(14 \delta, 149)$

$\mathrm{POF}\left(12 \delta^{*}, 12 \mathrm{q}\right)$

C)

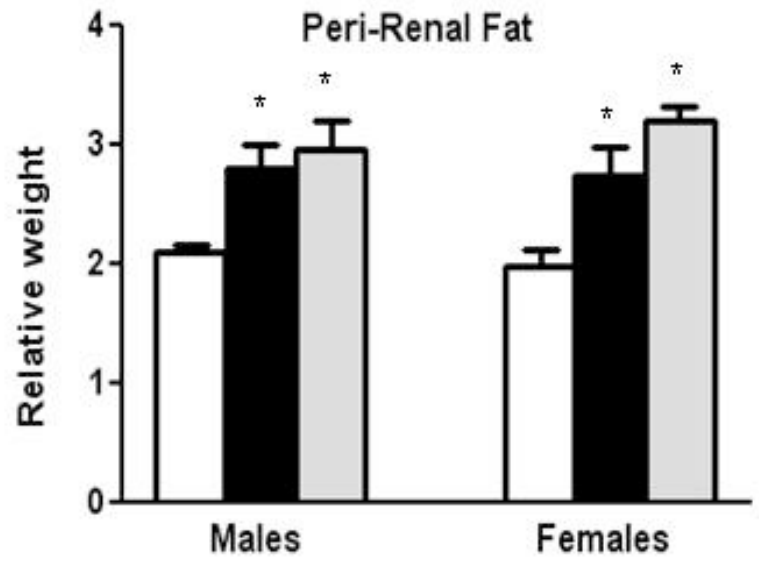

D)

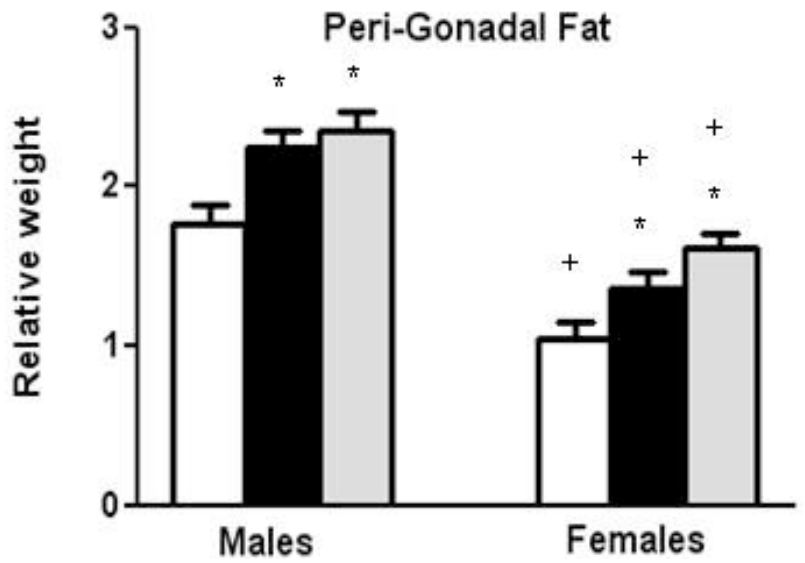

Fig. 3. Brown (A), subcutaneous (B), peri-renal (C) and peri-gonadal (D) adipose tissue weight relative to body weight in male and female MUN, C and POF offspring. C, rats with ad libitum diet in pregnancy and 12 rats/litter; MUN, rats exposed to $50 \%$ of the normal daily intake during the second half of pregnancy and 12 rats/litter; POF, rats with ad libitum diet during pregnancy and 4 pups/litter. In parenthesis is shown the number of rats; ${ }^{*} p<0.05$ when compared to $C$ group; ${ }^{+} p<0.05$ when compared to male rats. 
A)

Mesenteric Fat

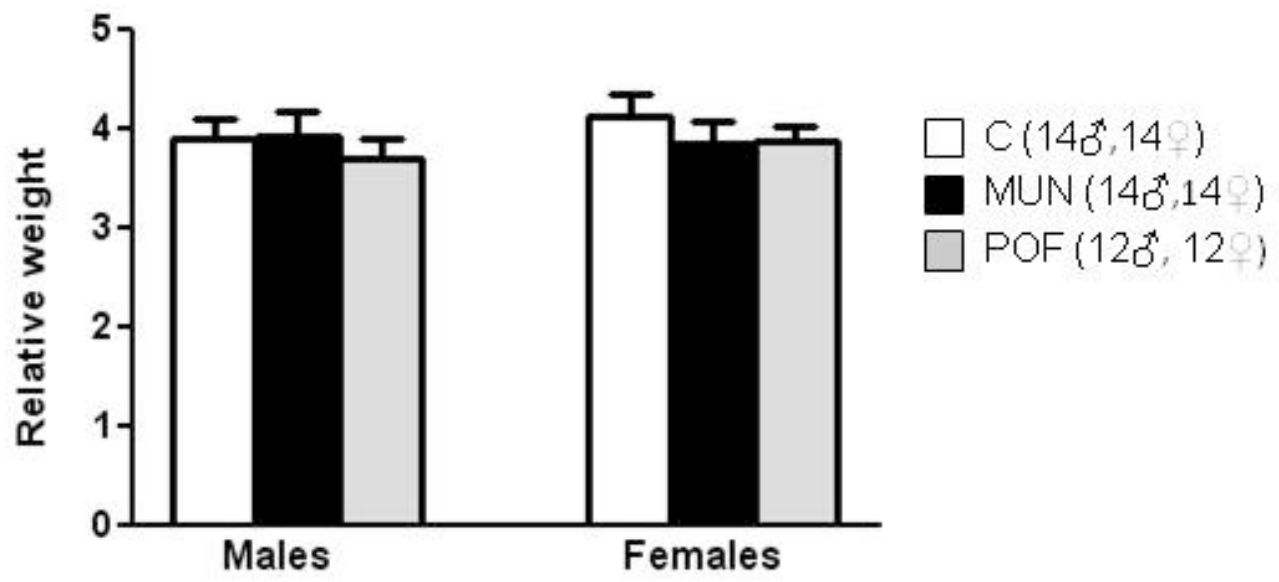

B)
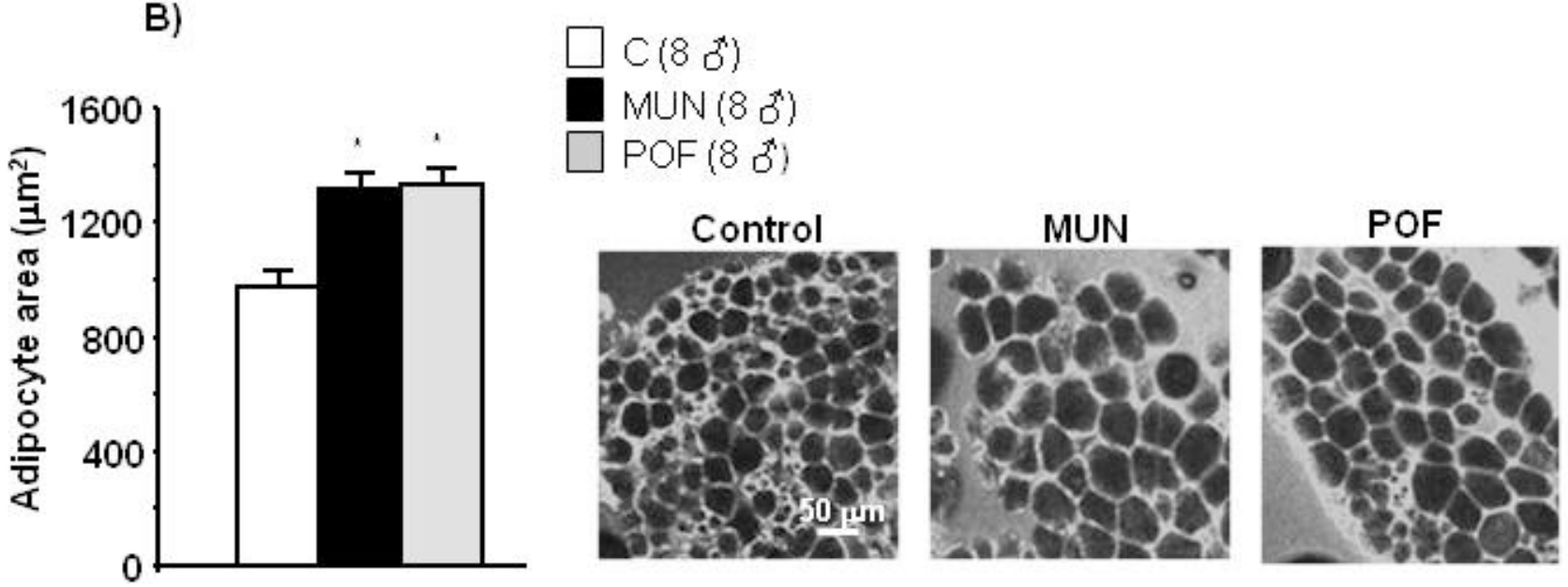

Fig. 4. (A) Mesenteric adipose tissue weight relative to body weight in male and female MUN, $C$ and POF offspring. (B) Mean adipocyte area and representative confocal images from mesenteric perivascular fat obtained from male MUN, C and POF offspring. C, rats with ad libitum diet in pregnancy and 12 rats/litter; MUN, rats exposed to $50 \%$ caloric intake during pregnancy and 12 rats/litter; POF, rats with ad libitum diet during pregnancy and 4 pups/litter. In parenthesis is shown the number of rats; $* \mathrm{p}<0.05$ when compared to $\mathrm{C}$ group.

\section{Adipose tissue content}

Male MUN rats exhibited similar brown adipose tissue content compared to male $\mathrm{C}$ rats. POF males tended to have larger brown tissue deposits, but did not reach statistical significance $(p=0.07)$. In female rats brown tissue content was not statistically different among the experimental groups (Fig. 3A).

Subcutaneous fat was significantly higher in both male and female MUN and POF rats compared to their respective sex-matched controls. There was no statistical difference between sexes in any of the experimental groups (Fig. 3B).

Peri-renal fat was significantly larger in MUN and $\mathrm{POF}$ rats compared to $\mathrm{C}$ in both male and female rats with no significant difference between sexes in any experimental group (Fig. 3C). Peri-gonadal fat was also larger in male and female MUN and POF rats compared to sex-matched controls. Male rats had significantly larger peri-gonadal fat contents compared to female counterparts in all experimental groups (Fig. 3D). There were no differences between MUN and POF offspring in any of the visceral fat content.

Mesenteric fat weight was not statistically different among experimental groups (Fig. 4A). In order to assess possible differences in adipocyte size we obtained a sample from mesenteric perivascular fat in a group of male rats. Adipocyte size was significantly larger in MUN and POF male offspring compared to $\mathrm{C}$ rats and no differences between MUN and POF adipocytes were detected (Fig. 4B). 


\section{Discussion}

Fetal undernutrition is a risk factor for development of cardiometabolic diseases and seems to have a sex-dependent component. However, it is not clear the relative role of fetal insult per se and postnatal catchup growth. Moreover, there is also unclear whether female protection against fetal programming occurs during perinatal development or later in life due to the effects of estrogen protection. This controversy is likely due to the fact that most of the studies have been carried out in adult animals, when many factors already came into play. Therefore, we aimed to address these questions through a study during critical windows of postnatal development. Since maternal nutritional status has been proposed to be the major programming influence on the developing fetus, we compared the alterations induced in the offspring of rats exposed to maternal undernutrition (MUN), a model of fetal programming, with those induced by postnatal overfeeding (POF) without prior fetal stress.

The main findings from our study are the similarities at weaning between MUN and POF models in terms of hyperglycemia, liver hypertrophy and fat accumulation. These data suggest that accelerated growth during the perinatal life might lead to key changes for later metabolic disease programming, independently of the existence of a prior fetal stress. Moreover, in the long run, the increased early fat accumulation -particularly visceral fat- might also contribute to cardiovascular damage. On the other hand, early heart hypertrophy and a mild kidney reduction were present exclusively in MUN offspring, suggesting that fetal stress might have a higher impact on hypertension development and cardiovascular disease programming, compared to nutritional interventions during postnatal life. Additionally, our study demonstrates that there are no major sex differences before sexual maturity, suggesting that the female protection against fetal programming might be related to the effects of sex hormones, rather to advanced organ maturation. We cannot rule out, however, sexdifferences at molecular or biochemical level not assessed in the present study.

\section{Selection of animal models}

Intrauterine growth retardation may be induced experimentally by several means. We used a rat model of maternal undernutrition, in which dams are food restricted during the second half of gestation, for several reasons. Firstly, this intervention induces low birth weight and development of hypertension (Khorram et al. 2007, Vehaskari and Woods 2005) and obesity (Desai et al. 2005) in adult rats. Secondly, the last half of gestation has been shown to be critical for rat nephrogenesis (Paixao and Alexander 2013) and for CMD development in humans (Barker 1995, Barker et al. 1993).

To assess the role of postnatal accelerated growth we used a model of postnatal overfeeding induced by litter size reduction, since it has been demonstrated that the amount of milk intake is inversely proportional to litter size (Babický et al. 1973, Balonan and Sheng 2000). We avoided cross-fostering of newborn pups to dams with normal food intake during pregnancy - another common method to determine the relative importance of pregnancy or suckling period in disease programming since there is evidence that cross-fostering itself can alter cardiovascular and metabolic function in rodents (Matthews et al. 2011).

We studied the animals at weaning. Physiological weaning is the time when the young first start taking food other than maternal milk, and has been described to be initiated by the age of 15 days (Babický et al. 1973). However, the end of weaning period, when the animals are separated from the mother, varies among different breeders from day 19 to 28 of age. We are aware that comparison of different weaning ages might lead to confounding results (Kunes et al. 2012) making difficult the interpretation of our data in comparison to others. Therefore, we weaned the rats at the age of 21 days to match the majority of studies in the field of nutritional influences of fetal and perinatal programming of CMD using the rat as experimental model (Balonan and Sheng 2000, Ozaki et al. 2001, Khorram et al. 2007, Ojeda et al. 2007, Moreira et al. 2009, Suzuki et al. 2010, Howie et al. 2012).

Role of fetal undernutrition versus catch-up growth in programming of metabolic alterations

Catch-up growth refers to accelerated gain in height, weight, or both, in postnatal life. This can be brought by artificial overfeeding or by a compensatory mechanism in offspring exposed to fetal suboptimal nutrition to balance intrauterine growth impairment. Some authors postulate that this compensatory growth after in utero nutrient restriction is the causal link between fetal malnutrition and CMD disease development later in life, rather than fetal programming per se (Singhal and Lucas 2004). We found that dietary 
restriction during the second half of pregnancy induced a smaller weight gain in the dams and a subsequent reduction of offspring birth weight. During lactation MUN dams increase their food intake, in an effort to recover body weight, as previously described (Howie et al. 2012). We did not find differences in dam food intake in the last period of lactation, likely due to the initiation of solid food eating by the offspring after day 15 (Babický et al. 1973).

MUN offspring accelerated their growth along postnatal period and, by the age of 21 days, they reached the same body weight and tibial length as their sexmatched controls. These results are in agreement with catch-up growth reported in other rodent models of intrauterine growth retardation where the animals reached the same (Ozaki et al. 2001) or even larger body weight than controls (Desai et al. 2005) at 21 days of age. The increased rate of postnatal growth in the latter study compared to ours might be related either to the lower number of animals per litter ( 8 rats compared to 12 in the present study) or to cross-fostering, which has been demonstrated to increase appetite (Matthews et al. 2011).

Postnatal overfeeding, induced by reduction of litter size to 4 rats, without prior fetal insult, also led to accelerated growth along postnatal development. This is due to the increase in milk intake which has been demonstrated to be inversely proportional to litter size (Balonan and Sheng 2000). It has been demonstrated that growth rates of rats during suckling period is maximum during the first week of life and gradually decreases reaching a minimum at day 17 (Babický et al. 1973). Our data indicate that this the first week of life, when the animals depend solely on milk, also seems to be important in the process of growth acceleration. Thus, by day 7, both MUN and POF offspring multiplied by 3 their body weight, compared to controls which only doubled weight. Growth acceleration during the perinatal period was associated with excess adipose tissue accumulation, and this alteration was independent of a prior fetal undernutrition. This excess fat has been demonstrated to remain elevated in adult rats (Howie et al. 2012, Suzuki et al. 2010), but it can be prevented by a reduction of mother intake during lactation (Howie et al. 2012). The present data indicate the key influence of suckling period for early fat accumulation and support the importance to avoid postnatal growth acceleration thought breastfeeding patterns to reduce the risk of CMD programming in humans (Singhal 2006).

Increased total fat content has been previously reported at an early age by DEXA scanning (Desai et al. 2005, Howie et al. 2012). The present study adds information showing that increased adiposity in MUN and POF rats was located not only in subcutaneous tissue, but also around the viscera. The lack of differences in mesenteric fat weight was probably due to inaccuracy of quantification, since it was weighted together with the vascular system. We confirmed the increase in mesenteric fat content MUN and POF by the larger adipocyte size in both models. In addition to metabolic consequences, this early perivascular fat accumulation might be relevant as cardiovascular risk factor later in life. We have demonstrated that in initial stages of obesity it might be beneficial (Gil-Ortega et al. 2010); but in the long run excessive perivascular fat undergoes important structural and functional changes contributing to endothelial dysfunction and cardiovascular disease development (Fernández-Alfonso et al. 2013, Gil-Ortega et al. 2014).

The similarities between MUN and POF offspring indicate that, although the increased in efficiency to store fat can be programmed during fetal life, through early induction of adipogenic transcription factors (Desai and Ross 2011), the postnatal period is also critical and an excess intake during suckling period produces the same effects. This is further supported by the similar amount of fat found in MUN fetus compared to controls (Nguyen et al. 2010).

We also found identical patterns of liver hypertrophy and hyperglycemia in MUN and POF offspring. Previous reports demonstrate liver enlargement and altered enzymatic systems in adult male rats exposed to fetal undernutrition, which are abolished if postnatal catch-up growth does not take place (Howie et al. 2012). Moreover, hyperglycemia has been previously found in overfed animals together with an increased fatty acid synthase and lipogenic activities in adipose tissues at weaning (Balonan and Sheng 2000). All these data support the important role of postnatal feeding patterns, independently of fetal stress, in the development of metabolic alterations.

Role of fetal undernutrition versus catch-up growth in programming of cardiovascular disease

Fetal nutrient restriction in rats has been implicated in the development of cardiovascular alterations, particularly hypertension (Langley-Evans 1999, Khorram et al. 2007). Therefore, we explored whether heart or kidney, key organs for cardiovascular control were affected at an early age and the role of 
catch-up growth.

A reduction in kidney mass and nephron number has been postulated as a potential mechanism implicated in fetal programming of hypertension (Nuyt 2008) and the last 2 weeks of gestation seem to be a crucial period whereby undernutrition can compromise nephrogenesis in the rat (Paixao and Alexander 2013). In our MUN model females did not show kidney differences and male offspring only evidenced a tendency to have smaller kidneys, near statistical significance, and much milder compared to the effects produced by maternal protein restriction (Langley-Evans et al. 1999) or uterine artery ligation (Vehaskari et al. 2001). It is possible that the severity of fetal stress induced by global nutrient restriction is smaller compared to other interventions. It is also possible that other alterations, not determined in the present study, such as nephron number or function might be present in our MUN model.

Increased ventricular weight at weaning was only observed in MUN, but not in POF offspring, suggesting that it is programmed in utero. The importance of the fetal period for heart growth is evidenced by the observed increased insulin-like growth factor gene expression in hearts of lamb fetus exposed to intrauterine growth retardation (Wang et al. 2011). During fetal period there is extensive hyperplasia in the rat heart which continues until postnatal day 5 ; thereafter the heart enlarges mainly by cell hypertrophy (Zicha and Kunes 1999). We did not test whether the observed MUN heart enlargement at the age of 21 days was due to initial hyperplasia, later cell hypertrophy or both. We have evidence that by day 7 , hearts from MUN offspring already tend to be larger, but did not reach statistical significance until weaning (Arribas et al. 2012), suggesting that the postnatal catch-up growth period plays a role. On the other hand, postnatal catch-up growth without a prior fetal stress does not seem to initiate heart hypertrophy, as shown by the lack of effect in POF rats. This is in contrast with the data of Moreira et al. (2009) who found that postnatal overfeeding induced heart hypertrophy in Wistar rats. This discrepancy can be explained by differences in the growth rates of Wistar and Sprague Dawley rats or by the fact that only overweight animals were selected in their work. We would like also to point out at the possible differences, between ours and other studies depending on the time of rat weaning, which might be important for organ development (Zicha and Kunes 1999). We also have evidence that MUN hearts exhibit an early increase in collagen content (Arribas et $a l$. 2012), which has been also observed in adult offspring from rats exposed to protein deficiency in pregnancy (Kawamura et al. 2007). The progression of cardiac alterations in MUN offspring and their role on hypertension development needs to be further evaluated.

\section{Sex-dependent effects}

Fetal programming in animal models has been shown to exhibit a sex dependent pattern, being females protected (Grigore et al. 2008). Thus, moderate global dietary restriction during gestation in the rat leads to hypertension which is more pronounced and develops earlier in male offspring (Ozaki et al. 2001) and liver and cholesterol alterations are found only in male rats (Howie et al. 2012). Whether this sexual dimorphism is related to perinatal programming itself or to the later protection of female sex hormones (Grigore et al. 2008, Jones et al. 2012) is still under debate. Our data showing identical alterations in MUN and POF males and females before sexual maturity support a later protective role of female sex hormones, as previously suggested. For example the fact that hypertension induced in the offspring of rats exposed to placental insufficiency is normalized in females after puberty (Alexander 2003, Jones et al. 2012). Moreover, blood pressure is significantly increased following ovariectomy in adult female growth restricted offspring (Ojeda et al. 2007). Taken all together, the present data showing that males and females exposed to undernutrition during fetal life, exhibit similar catch-up growth and organ alterations prior to sexual maturity, support the role of female hormones in the later protection against cardiometabolic programming. However, we cannot rule out other early differences, between males and females, for example at molecular or biochemical level, which were not studied in the present work and could also participate in the development of the sex-dependent cardiovascular and metabolic phenotype in adult life.

\section{Conflict of Interest}

There is no conflict of interest.

\section{Acknowledgements}

Supported by grants of Ministerio de Economía y competitividad (FEM2009-13434-C02-02 and FEM201237634-C03-01). 


\section{References}

ALEXANDER BT: Placental insufficiency leads to development of hypertension in growth-restricted offspring. Hypertension 41: 457-462, 2003.

ARENZ S, RUCKERL R, KOLETZKO B, VON KRIES R: Breast-feeding and childhood obesity - a systematic review. Int J Obes Relat Metab Disord 28: 1247-1256, 2004.

ARRIBAS SM, LOPEZ DE PABLO AL, PRACHANEY P, CONDEZO-HOYOS L, RODRIGUEZ-RODRIGUEZ P, REGADERA JF, LÓPEZ-GIMÉNEZ MR, GONZALEZ MC: Maternal undernutrition in rats induces early heart hypertrophy in young male and female offspring. Acta Physiol (Oxf) 206 (Suppl 693): abstract O167, 2012.

BABICKÝ A, PARÍZEK J, OSTÁDALOVÁ I, KOLÁR J: Initial solid food intake and growth of young rats in nests of different sizes. Physiol Bohemoslov 22: 557-566, 1973.

BALONAN LC, SHENG HP: Perinatal feedings adversely affect lipogenic activities but not glucose handling in adult rats. Pediatr Res 48: 668-673, 2000.

BARKER DJ: Fetal origins of coronary heart disease. BMJ 311: 171-174, 1995.

BARKER DJ, OSMOND C: Infant mortality, childhood nutrition, and ischaemic heart disease in England and Wales. Lancet 1: 1077-1081, 1986.

BARKER DJ, HALES CN, FALL CH, OSMOND C, PHIPPS K, CLARK PM: Type 2 (non-insulin-dependent) diabetes mellitus, hypertension and hyperlipidaemia (syndrome $\mathrm{X}$ ): relation to reduced fetal growth. Diabetologia 36: 62-67, 1993.

BATESON P, BARKER D, CLUTTON-BROCK T, DEB D, D'UDINE B, FOLEY RA, GLUCKMAN P, GODFREY K, KIRKWOOD T, LAHR MM, MCNAMARA J, METCALFE NB, MONAGHAN P, SPENCER HG, SULTAN SE: Developmental plasticity and human health. Nature 430: 419-421, 2004.

CORPELEIJN WE, KOUWENHOVEN SM, VAN GOUDOEVER JB: Optimal growth of preterm infants. World Rev Nutr Diet 106: 149-155, 2013.

DESAI M, ROSS MG: Fetal programming of adipose tissue: effects of intrauterine growth restriction and maternal obesity/high-fat diet. Semin Reprod Med 29: 237-245, 2011.

DESAI M, GAYLE D, BABU J, ROSS MG: Programmed obesity in intrauterine growth-restricted newborns: modulation by newborn nutrition. Am J Physiol Regul Integr Comp Physiol 288: R91-R96, 2005.

FERNANDEZ-ALFONSO MS, GIL-ORTEGA M, GARCÍA-PRIETO CF, ARANGUREZ I, RUIZ-GAYO M, SOMOZA B: Mechanisms of perivascular adipose tissue dysfunction in obesity. Int J Endocrinol 2013: 402053, 2013.

GIL-ORTEGA M, STUCCHI P, GUZMAN-RUIZ R, CANO V, ARRIBAS S, GONZALEZ MC, RUIZ-GAYO M, FERNANDEZ-ALFONSO MS, SOMOZA B: Adaptative nitric oxide overproduction in perivascular adipose tissue during early diet-induced obesity. Endocrinology 151: 3299-3306, 2010.

GIL-ORTEGA M, CONDEZO-HOYOS L, GARCÍA-PRIETO CF, ARRIBAS SM, GONZÁLEZ MC, ARANGUEZ I, RUIZ-GAYO M, SOMOZA B, FERNÁNDEZ-ALFONSO MS: Imbalance between pro and anti-oxidant mechanisms in perivascular adipose tissue aggravates long-term high-fat diet-derived endothelial dysfunction. Plos One 9: e95312, 2014.

GLUCKMAN PD, HANSON MA, COOPER C, THORNBURG KL: Effect of in utero and early-life conditions on adult health and disease. N Engl J Med 359: 61-73, 2008.

GRIGORE D, OJEDA NB, ALEXANDER BT: Sex differences in the fetal programming of hypertension. Gend Med 5 (Suppl A): S121-S132, 2008.

HABBOUT A, LI N, ROCHETTE L, VERGELY C: Postnatal overfeeding in rodents by litter size reduction induces major short- and long-term pathophysiological consequences. J Nutr 143: 553-562, 2013.

HEIJMANS BT, TOBI EW, STEIN AD, PUTTER H, BLAUW GJ, SUSSER ES, SLAGBOOM PE, LUMEY LH: Persistent epigenetic differences associated with prenatal exposure to famine in humans. Proc Natl Acad Sci USA 105: 17046-17049, 2008. 
HOWIE GJ, SLOBODA DM, VICKERS MH: Maternal undernutrition during critical windows of development results in differential and sex-specific effects on postnatal adiposity and related metabolic profiles in adult rat offspring. Br J Nutr 108: 298-307, 2012.

HUXLEY R, OWEN CG, WHINCUP PH, COOK DG, RICH-EDWARDS J, SMITH GD, COLLINS R: Is birth weight a risk factor for ischemic heart disease in later life? Am J Clin Nutr 85: 1244-1250, 2007.

JONES JE, JURGENS JA, EVANS SA, ENNIS RC, VILLAR VA, JOSE PA: Mechanisms of fetal programming in hypertension. Int J Pediatr 2012: 584831, 2012.

KAWAMURA M, ITOH H, YURA S, MOGAMI H, SUGA S, MAKINO H, MIYAMOTO Y, YOSHIMASA Y, SAGAWA N, FUJII S: Undernutrition in utero augments systolic blood pressure and cardiac remodeling in adult mouse offspring: possible involvement of local cardiac angiotensin system in developmental origins of cardiovascular disease. Endocrinology 148: 1218-1225, 2007.

KERKHOF GF, WILLEMSEN RH, LEUNISSEN RW, BREUKHOVEN PE, HOKKEN-KOELEGA AC: Health profile of young adults born preterm: negative effects of rapid weight gain in early life. $J$ Clin Endocrinol Metab 97: 4498-4506, 2012.

KHORRAM O, MOMENI M, DESAI M, ROSS MG: Nutrient restriction in utero induces remodeling of the vascular extracellular matrix in rat offspring. Reprod Sci 14: 73-80, 2007.

KUNES J, KADLECOVA M, VANECKOVA I, ZICHA J: Critical developmental periods in the pathogenesis of hypertension. Physiol Res 61 (Suppl 1): S9-S17, 2012.

LANGLEY-EVANS SC, WELHAM SJ, JACKSON AA: Fetal exposure to a maternal low protein diet impairs nephrogenesis and promotes hypertension in the rat. Life Sci 64: 965-974, 1999.

LUMEY LH, STEIN AD, KAHN HS, ROMIJN JA: Lipid profiles in middle-aged men and women after famine exposure during gestation: the Dutch Hunger Winter Families Study. Am J Clin Nutr 89: 1737-1743, 2009.

MATTHEWS PA, SAMUELSSON AM, SEED P, POMBO J, OBEN JA, POSTON L, TAYLOR PD: Fostering in mice induces cardiovascular and metabolic dysfunction in adulthood. $J$ Physiol 589: 3969-3981, 2011.

MOREIRA AS, TEIXEIRA TEIXEIRA M, DA SILVEIRA OSSO F, PEREIRA RO, DE OLIVEIRA SILVA-JUNIOR G, GARCIA DE SOUZA EP, MANDARIM DE LACERDA CA, MOURA AS: Left ventricular hypertrophy induced by overnutrition early in life. Nutr Metab Cardiovasc Dis 19: 805-810, 2009.

NGUYEN LT, MUHLHAUSLER BS, BOTTING KJ, MORRISON JL: Maternal undernutrition alters fat cell size distribution, but not lipogenic gene expression, in the visceral fat of the late gestation guinea pig fetus. Placenta 31: 902-909, 2010.

NIELSEN MO, KONGSTED AH, THYGESEN MP, STRATHE AB, CADDY S, QUISTORFF B, JORGENSEN W, CHRISTENSEN VG, HUSTED S, CHWALIBOG A, SEJRSEN K, PURUP S, SVALASTOGA E, MCEVOY FJ, JOHNSEN L: Late gestation undernutrition can predispose for visceral adiposity by altering fat distribution patterns and increasing the preference for a high-fat diet in early postnatal life. Br J Nutr 109: 2098-2110, 2013.

NORMAN M: Preterm birth - an emerging risk factor for adult hypertension? Semin Perinatol 34: 183-187, 2010.

NUYT AM: Mechanisms underlying developmental programming of elevated blood pressure and vascular dysfunction: evidence from human studies and experimental animal models. Clin Sci (Lond) 114: 1-17, 2008.

OJEDA NB, GRIGORE D, ROBERTSON EB, ALEXANDER BT: Estrogen protects against increased blood pressure in postpubertal female growth restricted offspring. Hypertension 50: 679-685, 2007.

OZAKI T, NISHINA H, HANSON MA, POSTON L: Dietary restriction in pregnant rats causes gender-related hypertension and vascular dysfunction in offspring. J Physiol 530:141-152, 2001.

PAIXAO AD, ALEXANDER BT: How the kidney is impacted by the perinatal maternal environment to develop hypertension. Biol Reprod 89: 1-10, 2013.

POSTON L: Influence of maternal nutritional status on vascular function in the offspring. Microcirculation 18: 256$262,2011$.

RAVELLI AC, VAN DER MEULEN JH, MICHELS RP, OSMOND C, BARKER DJ, HALES CN, BLEKER OP: Glucose tolerance in adults after prenatal exposure to famine. Lancet 351: 173-177, 1998.

SINGHAL A: Early nutrition and long-term cardiovascular health. Nutr Rev 64: S44-S49, 2006. 
SINGHAL A, LUCAS A: Early origins of cardiovascular disease: is there a unifying hypothesis? Lancet 363: 1642$1645,2004$.

SUZUKI M, SHIBANUMA M, KIMURA S: Effect of severe maternal dietary restriction on growth and intraabdominal adipose tissue weights in offspring rats. J Nutr Sci Vitaminol (Tokyo) 56: 293-298, 2010.

VEHASKARI VM, WOODS LL: Prenatal programming of hypertension: lessons from experimental models. $J$ Am Soc Nephrol 16: 2545-2556, 2005.

VEHASKARI VM, AVILES DH, MANNING J: Prenatal programming of adult hypertension in the rat. Kidney Int 59: 238-245, 2001.

WANG KC, ZHANG L, MCMILLEN IC, BOTTING KJ, DUFFIELD JA, ZHANG S, SUTER CM, BROOKS DA, MORRISON JL: Fetal growth restriction and the programming of heart growth and cardiac insulin-like growth factor 2 expression in the lamb. $J$ Physiol 589: 4709-4722, 2011.

ZICHA J, KUNES J: Ontogenic aspects of hypertension development: analysis in the rat. Physiol Rev 79: 1227-1282, 1999. 